\title{
Remanufacturing for Circular Economy: Understanding the Impact of Manufacturer's Incentive under Price Competition
}

\author{
Deepak Singhal ${ }^{1}$, Sarat Kumar Jena ${ }^{2}\left(\mathbb{D}\right.$, Satyabrata Aich ${ }^{3} \mathbb{D}$, Sushanta Tripathy ${ }^{1, * \mathbb{C}}$ and Hee-Cheol Kim ${ }^{4, *}$ \\ 1 School of Mechanical Engineering, KIIT Deemed to be University, Bhubaneswar, Odisha 751024, India; \\ deepak.singhalfme@kiit.ac.in \\ 2 Operations Management School, Xavier Institute of Management, XIM University, Bhubaneswar, \\ Odisha 751024, India; saratkumar.jena@gmail.com \\ 3 Wellmatix Co., Ltd., Changwon 51395, Korea; satyabrataaich@gmail.com \\ 4 College of AI Convergence/Institute of Digital Anti-aging Healthcare/u-AHRC, Inje University, \\ Gimhae 50834, Korea \\ * Correspondence: sushant.tripathy@gmail.com (S.T.); heeki@inje.ac.kr (H.-C.K.); \\ Tel.: +82-55-320-3720 (H.-C.K.)
}

Citation: Singhal, D.; Jena, S.K.; Aich, S.; Tripathy, S.; Kim, H.-C.

Remanufacturing for Circular

Economy: Understanding the Impact of Manufacturer's Incentive under Price Competition. Sustainability 2021, 13, 11839. https://doi.org/10.3390/ su132111839

Academic Editor: Antonella Petrillo

Received: 28 September 2021

Accepted: 21 October 2021

Published: 26 October 2021

Publisher's Note: MDPI stays neutral with regard to jurisdictional claims in published maps and institutional affiliations.

Copyright: (c) 2021 by the authors. Licensee MDPI, Basel, Switzerland. This article is an open access article distributed under the terms and conditions of the Creative Commons Attribution (CC BY) license (https:// creativecommons.org/licenses/by/ $4.0 /)$.

\begin{abstract}
Business organizations all around the globe are looking to expand circular models into their supply chains to harness economic and environmental benefits. Moreover, the act of giving incentives to retailers by the manufacturer is also quite prevalent in the present business environment. These incentives are offered to promote the sales of products of a manufacturer. Therefore, this paper examines the optimal decisions for a dual-retailer closed-loop supply chain (CLSC) in which the manufacturer bestows the credit period to the one retailer (a firm that possesses shallow market penetration and has a higher insistence on the usage of the capital venture), and cash discount to the next retailer (a firm that occupies the market to a greater extent and receives lower thrust on the usage of invested capital) under a non-coordinated system and coordinated systems. This study proposes the mathematical model to determine the optimal decisions of the manufacturer in terms of credit period and cash discount and also compute the optimal decisions of the retailers for their retail prices and order quantities to maximize individual's profit in the CLSC. Moreover, numerical analysis and sensitivity analysis is performed to get insights into the optimal decisions of the manufacturer and retailers. The results of sensitivity analysis show that credit period and cash discount increases with the rise in price elasticity, and decreases with an increase in cross-price elasticity. The findings also confirm that members of dual-retailer CLSC under coordination and manufacture's incentive scenario generate higher environmental and economic benefits required to attain sustainability in production and consumption.
\end{abstract}

Keywords: closed-loop supply chain (CLSC); supply chain coordination; incentive; credit period; cash discount; remanufacturing

\section{Introduction}

The concept of circular economy (CE) has gained popularity among manufacturing industries due to its untapped environmental and economic benefits. CE is a cyclic framework that aims to dispose of waste by turning products that are toward the end of their life cycle into resources for new ones [1,2]. The continual use of resources can be ensured in the industrial ecosystems by closing the material loops [3]. Thus, the calls for the development of a closed-loop supply chain (CLSC) are rapidly increasing to transition from linear economy to CE. A CLSC enables firms to have proficient utilization of resources and results in a positive effect on the environment and economy [4]. In the CLSC, end-of-life (EOL) and end-of-use (EOU) products may undergo recycling, repair, reuse, refurbishing, and remanufacturing after their disposal. However, only remanufacturing ensures that the nature of remanufactured products is on a standard with that of new items [5,6]. Remanufacturing is 
a process of bringing EOL and EOU products to a like-new condition. Remanufacturing involves the repair or refurbishment or replacement of obsolete and worn-out parts [7]. Remanufacturing offers potential benefits to the environment by extending the life cycle of the EOL and EOU products. For instance, remanufacturing results in the reduction of materials and energy consumption and reduces the need to landfill waste products $[8,9]$. Remanufacturing is being practiced widely by various organizations such as IBM, HP, Fujifilm, Kodak, Caterpillar, etc. Awan et al. [10] explained that firms have adopted industry 4.0 technologies such as internet of things (IoT) to make the remanufacturing process more effective and efficient.

Many factors, for example, promotion, warranty, government incentives, different types of discounts, rebates, and so forth impact the decisions of supply chain members in the competitive business condition. It is also prevalent in the present business scenario to provide incentives to retailers by the manufacturers as a sales promotion tool [11]. In CLSC, firms work cohesively with the policymakers to shape the incentives, which create a positive impact on the firms and society. These incentives are offered to promote the sales of products of a manufacturer. Giri et al. [12] and Feng et al. [13] have suggested that a manufacturer can offer either the credit period or the cash discount as an incentive to the retailer. The manufacturer provides the credit period to a firm that possesses shallow market penetration and has a higher insistence on the usage of the capital venture [14], whereas the cash discount is offered to a firm that occupies the market to a greater extent and receives a lower thrust on the usage of invested capital. Kim et al. [15] investigated the optimum credit period that a supplier can provide to the retailer in order to maximize his profit in a single-retailer supply chain. Feng et al. [13] also suggested that a retailer decides on the optimal payment time by striking a balance between the benefits of cash discount and delay period in a single-retailer supply chain. Shah and Cárdenas-Barrón [16] investigated the decision of retailers for the deteriorating items under cash discount and credit period given by the supplier. Chung et al. [17] developed the inventory models for perishable items under the credit and cash discount options. Hence, researchers have put constant efforts into understanding the decisions of SC members under the condition of cash discount and credit period in various supply chain models.

Existing literature on the incentives in CLSC shows that there are few studies that investigate the impact of government incentives and customer incentives on the decision variables of CLSC $[18,19]$. Jena et al. [20] demonstrated that incentives given to the manufacturers by the government enhance the return of the utilized items and benefit of the individuals in the CLSC under competition. Hong et al. [21] presented that local advertising is essential to augment the collection rate of used products and to garner more profits in the CLSC. Hosseini-Motlagh et al. [22] analyzed the producer's incentive given to the dealers to enhance the return of used products. Genc and Giovanni [23] investigated the return behaviors of consumers towards waste under fixed and variable rebate conditions. However, the impact of the manufacturer's incentive in the competitive CLSC under the condition of cash discount and credit period remains undiscovered. The adoption of innovative sales approaches and financial incentives become inevitable by the firms to transition successfully towards closed-loop business practices such as remanufacturing [4]. Moreover, there is a need to investigate the economic and environmental benefits generated due to the adoption of coordination strategy by the members of the supply chain under the manufacturer incentives. Nonetheless, an examination that looks at the effect of producer's incentives in terms of cash discount and credit period on the competing retailers in the CLSC is absent in the existing literature. Hence, to fill this gap, this paper investigates the effect of manufacturer's incentives on the decisions of retailers and a manufacturer under dual-retailer CLSC. The results of this study will help the decision-makers to get insights into the decisions and profit of CLSC members when a manufacturer provides incentives to the retailers.

Therefore, this study addresses the following research questions. (1) How do the retailers and a manufacturer in CLSC take decisions individually to optimize their profits 
under the condition of cash discount and credit period. (2) What is the impact of the coordination strategy on the decisions of CLSC members under the proposed incentives?

We have addressed the above-mentioned research questions in the following manner. Firstly, the authors considered the dual-retailer and single-manufacturer CLSC model, where a third party collects the used products from the market. The collector remunerates the fixed value $X$ to the consumers and offers the used item back to the manufacturer after adding its profit share. The producer offers both remanufactured and new items to the retailers at the declared wholesale value A. Moreover, the manufacturer provides a money rebate $d$ to the one retailer and a credit period $p$ to the next retailer. Secondly, mathematical models based on Stackelberg game theory were developed for determining the optimum decisions of the manufacturer, collector, and retailers. Here, the manufacturer acts as a Stackelberg leader and each retailer as a follower. Subsequently, we have used the backward induction approach for determining the optimal values of the price discount, credit period, retail price, and order quantity with respect to concerned CLSC members. Thirdly, a numerical study was performed to get insights into the decisions of CLSC members. Here, authors considered the numerical values of market size, price elasticity, cross-price elasticity, wholesale price, cost of manufacturing, the difference in manufacturing and remanufacturing cost, transfer price, the amount paid to customers, capital opportunity cost, and scaling parameter to understand the optimal decision of manufacturer, collector, and retailers. Fourthly, we conducted a sensitivity analysis to analyze the impact of market size, price elasticity, and cross-price elasticity on the optimal decisions of the manufacturer and retailers. Lastly, a mathematical model was developed and analyzed to understand the implications of coordination strategy on the dual-retailer CLSC under the manufacturer's incentive scenario. Here, the authors have illustrated the environmental and economic benefits of centralized decision making.

\section{Literature Review}

In the course of the last decade, the idea of the CE has gained popularity, and has particularly been identified with endeavors to accomplish a more sustainable society [24]. The CE assists with closing the loops of energy and materials to utilize the existing materials as opposed to manufacturing new ones and expanding the harm to the climate [25]. The CE model recommends that waste be limited and cycled. The 3R (Reduce, Reuse, Recycle) framework is considered as the most prominent framework of CE and is adopted in various public waste guidelines throughout the planet [2]. However, researchers have also proposed various other CE frameworks such as 4R (Reduce, Reuse, Recycle, Renew), 5R (Redesign, Reduction, Recovery, Recycle, Reuse), 7R (Redesign, Renew, Reduce, Reuse, Repair, Recover, Recycle), 9R (Refuse, Reuse, Reduce, Repair, Refurbish, Repurpose, Recycle, Remanufacture, Recover), etc. [26,27]. Remanufacturing is emerging as a sustainable strategy for meeting the broader objective of CE [28]. Remanufacturing provides numerous benefits to the environment, economy, and society [29]. For instance, remanufactured items take up to $85 \%$ less electric energy as compared to the energy required by the new counterpart [4,30]. Zhang et al. [31] stated that there is a reduction of $55 \mathrm{~kg}$ of steel and $565 \mathrm{~kg}$ of $\mathrm{CO}_{2}$ in remanufacturing an engine. Remanufacturing extends benefits to society by providing employment to both skilled and non-skilled workers [8]. The previous two decades have seen a colossal increase in research on remanufacturing and CLSC. Numerous logical and observational examinations have been completed in various zones of remanufacturing such as production planning, purchase intention, scheduling, acquisition management, pricing and warranty policies, sorting policies, network design, etc. [32-37]. Savaskan et al. [38] examined collection efforts, customer incentives, and pricing decisions in CLSC with three types of collection channels for used products. Further, Savaskan and van Wassenhove [39] considered the scenario of competing retailers and examined the pricing decisions and chain profit for the direct and indirect reverse channels. They found that chain profit for a direct channel depends on the scale of returns and for an indirect reverse channel depends upon the competitive interplay between the retailers. Choi 
et al. [40] introduced a scientific model where the client request is fulfilled by a brand-new item and remanufactured item. In addition, from the perspective of competition in the CLSC, Kumar Jena and Sarmah [41] considered the price competition between the two manufacturers and suggested that the global cooperative channel results in the highest profit in the CLSC. Mitra [42] explained that remanufacturing is always beneficial in a competitive duopoly CLSC. Wu [43] evaluated the profit of the supply chain and its members under both price and service competition between the remanufacturer and manufacturer with a single retailer. Wei and Zhao [35] illustrated the decision on optimal wholesale pricing, retail pricing, and rate of remanufacturing in fuzzy CLSC under retail competition. Huang [44] developed the models for remanufacturing with a trade-in strategy to determine the equilibrium decisions in a CLSC consisting of one producer and two contending retailers. Karimbadi et al. [45] presented the game models that determine the pricing and remanufacturing decisions in a Fuzzy CLSC with one manufacturer, two retailers, and one third-party collector. They also explained that the manufacturer earns more profit as a Stackelberg leader.

Further, manufacturers giving impetuses to retailers as a business advancement scheme is mainstream in the present business. Goyal [46] and Chung et al. [17] expressed that the two most promotional tools are reducing the purchase cost and a deferral in installment. Additionally, they proposed a mathematical model for determining the economic order quantity when a supplier gives a fixed time span to pay the amount for the purchased merchandise in the forward supply chain. Moriarty and Moran [47] emphasized the need for multiple-retailer channels to enhance customer satisfaction and awareness. Further, Kim et al. [15] built up an optimal policy for credit to enhance the merchant benefit with price-dependent demand equations in the forward supply chain. They determined the optimum value of the credit period that can be given by the supplier to the retailer. Chung [48] explained that the retailer orders a greater quantity of products if the supplier provider delays the period for the payment. In addition, Abad and Jaggi [49] presented the optimal policies for the consumers and seller based on the seller's opportunity cost of capital that is considered to be the linear function of the credit period. Huang and Chung [50] broadened the research of Goyal by fusing the cash discount with the credit period to reflect the real-life business solutions in the forward supply chain. Huang [51] formulated the models for a retailer's ordering policies under the scenario when both supplier and retailer provide a credit period to retailer and customers, respectively. Wallace et al. [52] emphasized the need for multiple-retailer channels to enhance customer satisfaction by providing a broad set of services to customers. Multiple channels help in reaching a large number of consumers who cannot be approached through a single channel. There are various industries such as apparel, electronics, sports merchandise, appliances, etc. which work on dual or multiple channels to augment the awareness among the customers and loyalty towards their products. Cai et al. [53] assessed the effect of various pricing schemes and discounts on the forward supply chain under the online and traditional channels. Liu et al. [54] studied the combined pricing and production decision for an online channel under various contract situations.

Furthermore, from the perspective of incentives and other impetus in the supply chain, Mitra and Webster [55] addressed the impact of government incentives on remanufacturing under competition. They found the positive impact of subsidies on remanufacturing activities. Tsao [56] determined the optimal decision of a supplier and competing retailers when the supplier provides incentives to the retailers in the forward supply chain. Further, Tsao and Sheen [57] determined the solution for an ideal supplier credit period and also addressed the pricing and multi-item replenishment decisions of a retailer intended to maximize the profit in the forward supply chain. Li et al. [58] examined the impact of EPR laws on the CLSC in which the manufacturer assigns the collection of utilized items to the outsider. Hong et al. [21] built the Stackelberg models to determine the optimal decisions on pricing, collection rate, and advertising in the CLSC. They also emphasized the role of cooperative advertising in centralized decision making. Jena et al. [20] investigated the 
influence of government subsidies on the profit and surplus in a CLSC and found that government subsidies given to a manufacturer result in maximum channel profit and surplus. Moreover, they investigated the case of a centralized system where two manufacturers and a single retailer make an alliance and decide on the optimal decision together. Supply chain coordination is a prominent strategy to ameliorate the performance of the supply chain [18]. This coordination can be accomplished when firms cooperate by sharing assets and data to have common goals adjusted to augment client value in the entire SC. Ruiz-Torres et al. [19] examined the supplier capacity contract in the CLSC for the case of incentives given to the return sources. Song and Chu [59] evaluated the strategies for incentives in the CLSC of the electric vehicle battery. Hosseini-Motlagh et al. [22] investigated the impact of economic incentives given by the manufacturer to the dealer to motivate them for the return of spare parts of the automobiles. Kharaji Manouchehrabadi [60] analyzed the impact of government incentives on the profit of CLSC for the collection and remanufacturing of solar cells used. Wang et al. [61] investigated the decisions of CLSC members in the decentralized and centralized system under government incentives. They found that centralized decision making provides maximum benefit to the CLSC Members.

\section{Research Gap}

The adoption of innovative sales approaches and financial incentives become inevitable by the firms to transit successfully towards closed business loop practices such as remanufacturing [4]. From the perspective of incentives in the CLSC, only the impact of government incentives and customer incentives are addressed in the existing literature [18-20,22,59]. However, manufacturers also provide incentives in terms of a cash discount and credit period to the retailers as a sales promotional tool in the supply chain. Nonetheless, the study related to the manufacturer's incentives for the sales promotion in CLSC under retail competition is missing. Therefore, this study contributes to the body of literature of CLSC by examining the influence of manufacturer's incentives on the optimal decisions of retailers and a manufacturer under retail competition. Moreover, this paper assesses the impact of coordination strategy under the manufacturer's incentives scenario to understand the economic and environmental benefits. Thus, as shown in Figure 1, authors have analyzed a dual-retailer and single-manufacturer CLSC where a manufacturer grants a cash discount $(d)$ to retailer $\mathrm{i}$ and credit period $(p)$ to retailer $\mathrm{j}$. Moreover, the optimal decisions of the CLSC members are obtained by developing the Stackelberg game model where the manufacturer acts as a leader and retailer as a follower. The Stackelberg game models are widely used by numerous researchers such as Che et al. [62], Wan et al. [63], Su et al. [64], Li et al. [65], etc. to determine the optimal decision variables in various settings.

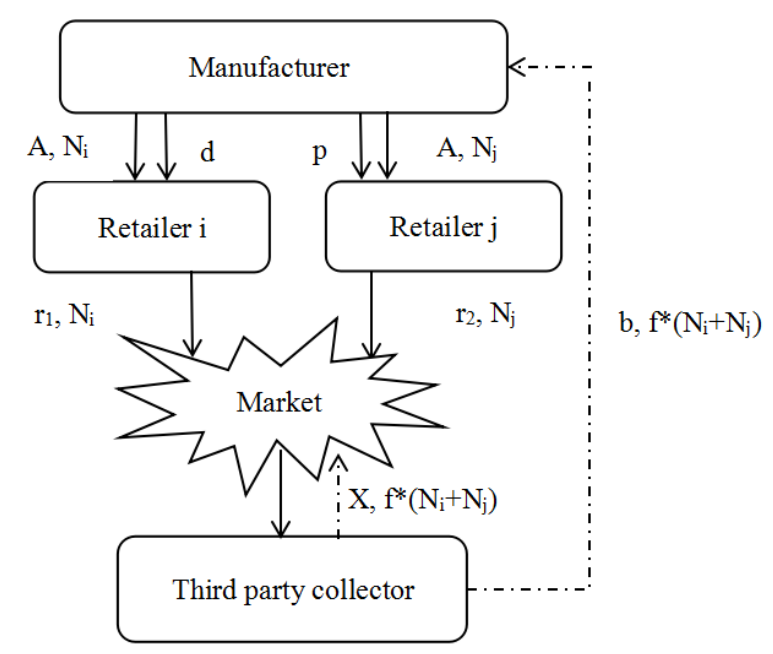

Figure 1. Remanufacturing system. 


\section{Key Assumptions and Notations}

The market activities and the $\mathrm{CE}$ are critical aspects to enhancing the market share in the present complex value chain. Shevchenko et al. [66] emphasized the need for incentives to promote and boost the implementation of the $\mathrm{CE}$ concept. Incentives help in combating market failures that forestall or defer the change towards circular items, administrations, and arrangements. Therefore, this study develops mathematical models to analyze the impact of a manufacturer's incentives on the decisions of channel partners under the retail competition in the CLSC. Figure 2 shows the framework developed by the authors to analyze the proposed model.

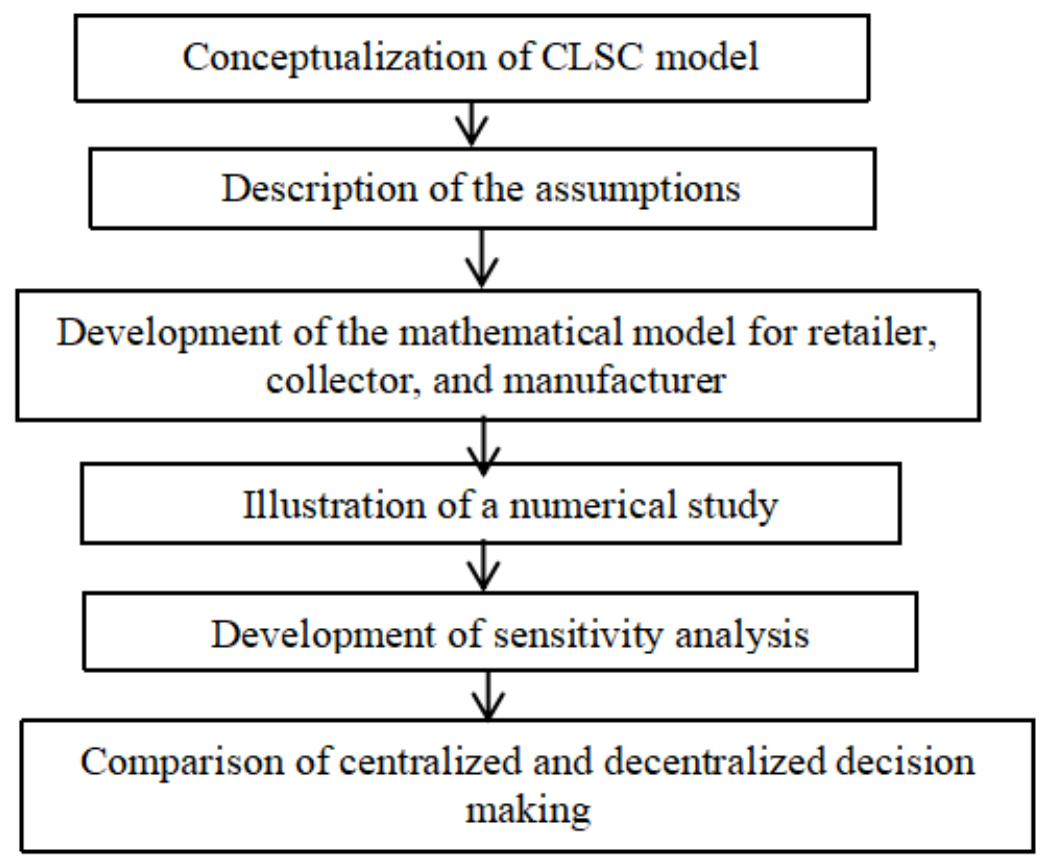

Figure 2. Proposed framework for the study.

In the proposed CLSC model, as shown in Figure 1, a manufacturer grants a cash discount $(d)$ to retailer $i$ and credit period $(p)$ to retailer $j$. Moreover, the manufacturer supplies both new and remanufactured products to both the retailers ( $i$ and $j$ ) at the announced wholesale price (A). Used products are collected by the third party $(t)$ and supplied to the manufacturer. Table 1 shows the notation used in this paper.

Table 1. Notation.

\begin{tabular}{cc}
\hline Symbol & Description \\
\hline$i, j$ & Retailer1, retailer2 \\
$m_{r}$ & manufacturer \\
$t$ & Third party collector \\
$r_{1}, r_{2}$ & Retail price for retailer i, retailer $\mathrm{j}$ \\
$d$ & Cash discount \\
$p$ & Credit period \\
$A$ & Declared wholesale price \\
$N_{i}, N_{j}$ & Order quantity by retailer i, retailer $\mathrm{j}$ \\
$\Pi_{m t}$ & Total profit of the manufacturer \\
$\Pi_{i}, \Pi_{j}$ & Profit of the retailer i, retailer $\mathrm{j}$ \\
$\Pi_{t}$ & Profit of the third party collector \\
$\Pi_{c t}$ & Total profit of non-coordinated system \\
$\Pi_{c c t}$ & Total profit of coordinated chain \\
\hline
\end{tabular}


Table 1. Cont.

\begin{tabular}{cc}
\hline Symbol & Description \\
\hline$\alpha_{1}, \alpha_{2}$ & Market size for retailer i, retailer $\mathrm{j}$ \\
$\beta_{1}, \beta_{2}$ & Price elasticity for retailer i, retailer $\mathrm{j}$ \\
$\gamma_{1}, \gamma_{2}$ & Cross price elasticity for retailer i, retailer $\mathrm{j}$ \\
$f$ & The fraction of the used products collected \\
$k$ & Capital opportunity cost \\
$b$ & Transfer price \\
$X$ & Amount paid to consumers \\
$m$ & Cost of manufacturing \\
$n$ & The difference between manufacturing and remanufacturing cost \\
$l$ & Collection parameter \\
\hline
\end{tabular}

This paper develops mathematical models under the following assumptions.

Assumption 1. The expense of the remanufactured item $(\mathrm{Cr} r)$ is less than the price of the brand-new product $(m)$, i.e., $\mathrm{Cr}<m$, and $\mathrm{Cr}$ is assumed to be the same for all the remanufactured products. Generally, the cost of a remanufactured product lies between $40 \%$ and $60 \%$ of the value of the new product $[30,67]$. This happens because remanufacturing consumes less material and less effort.

Assumption 2. The acquisition rate of the used items (f) decides the performance of the CLSC and the collective effort of the collector. The value of flies between 0 and 1 , and it is the function of a collection effort (E) put in by the retailer in collecting the used products; that is, $f=(E / l) 0.5$, where 1 is the sizeable positive scaling parameter [38]. The collection effort is typically demonstrated as the expense caused in gathering the utilized items.

Assumption 3. Transfer price (b) given by the producer to the third party is more than the amount given by the collector $(X)$ to the consumer for the utilized items, i.e., $b>X$. This is necessary from the point of view of a third-party collector. Otherwise, the collector will not be interested in collecting the used product from the market. Moreover, the collector pays the fixed price X for each used product irrespective of its quality.

Assumption 4. There is no distinction between the remanufactured items and new items, and both are sold at the same cost by the retailer. There are companies such as Kodak and Fujifilm that sell their remanufactured products and new products at the same selling price as there is no differentiation in the quality of both products $[41,68,69]$. Furthermore, it is assumed that the manufacturer has a great ability to fulfill the need of the retailer and there is no shortage.

Assumption 5. A retailer's demand depends on the competitor's retail price and its own retail price. As suggested by Tsao et al. [57] and Kumar Jena et al. [41], the demand function can be thought of as the accompanying structure, i.e., $N_{i}=\alpha_{1}-\beta_{1} \cdot r_{1}+\gamma_{1} \cdot r_{2}$ for the retailer $i$ and $N_{j}=\alpha_{2}-$ $\beta_{2} \cdot r_{2}+\gamma_{2} \cdot r_{1}$ for the retailer $j$. Moreover, demand is considered deterministic and non-stochastic. $\alpha_{1}>0$ and $\alpha_{2}>0$ represent the market size of retailer i's and retailer $j$ 's products, respectively. The parameters $\beta_{1}, \beta_{2}, \gamma_{1}$, and $\gamma_{2}$ are positive numbers and assumed to be independent in nature.

\section{Model Development}

Here, the authors develop the mathematical equations for the profit of retailer i, retailer $j$, third party, and manufacturer. Further, decisions of both the retailers, third party and manufacturer are evaluated using the optimization procedures.

\subsection{Retailers' Problem}

This section illustrates the decision of the retailer on the retail price and order quantity. The retailer $\mathrm{i}(\mathrm{j})$ determines the retail price $r_{1}\left(r_{2}\right)$ when the manufacturer grants the cash discount $d$ to the retailer $i$ and credit period $p$ to the retailer $j$. Consequently, the order quantity $N_{i}$ and $N_{j}$ are calculated for the retailer $\mathrm{i}$ and $\mathrm{j}$, respectively. The profit function for each retailer is written as follows: 
Profit of the retailer i:

$$
\Pi_{i}=\left(r_{1}-A(1-d)\right) N_{i}
$$

Profit of the retailer j:

$$
\Pi_{j}=\left(r_{2}-A\right) N_{j}+p A k N_{j}
$$

The authors have developed the expression for the profit $\Pi_{i}$ and $\Pi_{j}$ for the retailer i and $\mathrm{j}$, respectively. Now, the optimal value for the retail price $r_{1}\left(r_{2}\right)$ can be computed to maximize the profit of retailer $\mathrm{i}(\mathrm{j})$. We present propositions in order to understand the concavity and to obtain a unique solution for the profit of each retailer.

\subsubsection{Proposition}

(a) $\Pi_{i}$ and $\Pi_{j}$ are concave in $r_{1}$ and $r_{2}$, respectively.

(b) There exists an optimal value for retail price $r_{1}\left(r_{2}\right)$, which maximizes the profit function $\Pi_{i}\left(\Pi_{j}\right)$.

\section{Proof}

(a) $\frac{\partial^{2} \Pi_{i}}{\partial r_{1}{ }^{2}}=-2 \beta_{1}$ and $\frac{\partial^{2} \Pi_{j}}{\partial r_{2}{ }^{2}}=-2 \beta_{2}$ where $\beta_{1}, \beta_{2}>0$. Hence, $\frac{\partial^{2} \prod_{i}}{\partial r_{1}{ }^{2}}<0$ and $\frac{\partial^{2} \Pi_{j}}{\partial r_{2}{ }^{2}}<0$. This proves that $\Pi_{i}$ and $\Pi_{j}$ are concave in $\mathrm{r}_{1}$ and $\mathrm{r}_{2}$, respectively.

(b) The optimum value of $r_{1}$ can be obtained using the equation $\mathrm{f}\left(\mathrm{r}_{1}\right)=\frac{\partial \prod_{i}}{\partial r_{1}}=0$. Since $\frac{\partial^{2} \Pi_{i}}{\partial r_{1}{ }^{2}}<0, \mathrm{f}\left(r_{1}\right)$ is a decreasing function in $r_{1}$. As the value of $f(0)=0$ and $\mathrm{f}(\infty)=-\infty$, there exists a unique solution for $r_{1}$ (where $0<r_{1}<\infty$ ). Similarly, it can also be proved that there exists a unique solution for $r_{2}$.

Further, for the given value of $d$ and $p$, the simultaneous solution of equations $\frac{\partial^{2} \Pi_{i}}{\partial r_{1}{ }^{2}}=0$ and $\frac{\partial^{2} \Pi_{j}}{\partial r_{2}{ }^{2}}=0$ provides the optimum value of $r_{1}$ and $r_{2}$.

$$
\begin{gathered}
r_{1}=\left(2\left(\alpha_{1}-A(-1+d) \beta_{1}\right) \beta_{2}+\left(\alpha_{2}+A(1-k p) \beta_{2}\right) \gamma_{1}\right) /\left(4 \beta_{1} \beta_{2}-\gamma_{1} \gamma_{2}\right) \\
r_{2}=\left(2 \beta_{1}\left(\alpha_{2}+A(1-k p) \beta_{2}\right)+\left(\alpha_{1}-A(-1+d) \beta_{1}\right) \gamma_{2}\right) /\left(4 \beta_{1} \beta_{2}-\gamma_{1} \gamma_{2}\right)
\end{gathered}
$$

The optimum values of order quantity $\mathrm{N}_{\mathrm{i}}$ and $\mathrm{N}_{\mathrm{j}}$ are obtained by substituting the optimum values of $r_{1}$ and $r_{2}$ in the demand functions $N_{i}=\alpha_{1}-\beta_{1} \cdot r_{1}+\gamma_{1} \cdot r_{2}$ and $N_{j}=\alpha_{2}-\beta_{2} \cdot r_{2}+\gamma_{2} \cdot r_{1}$.

\subsubsection{Proposition}

(a) For the given $d$, the $r_{2}$ diminishes at a quicker rate in comparison to $r_{1}$ with $p$.

(b) For the given $p$, the $r_{1}$ diminishes at a quicker rate in comparison to $r_{2}$ with $d$.

\section{Proof}

(a) $\frac{\partial r_{1}}{\partial p}=-\left(\left(A k \beta_{2} \gamma_{1}\right) /\left(4 \beta_{1} \beta_{2}-\gamma_{1} \gamma_{2}\right)\right), \frac{\partial r_{2}}{\partial p}=-\left(\left(2 A k \beta_{1} \beta_{2}\right) /\left(4 \beta_{1} \beta_{2}-\gamma_{1} \gamma_{2}\right)\right)$ Since $\beta_{1}>\gamma_{1},\left|\frac{\partial r_{2}}{\partial p}\right|$ is greater than $\left|\frac{\partial r_{1}}{\partial p}\right|$. This proves that $r_{2}$ decreases at a faster rate in comparison to $r_{1}$ with $p$.

(b) $\frac{\partial r_{1}}{\partial d}=-\left(\left(2 A \beta_{1} \beta_{2}\right) /\left(4 \beta_{1} \beta_{2}-\gamma_{1} \gamma_{2}\right)\right), \frac{\partial r_{2}}{\partial d}=-\left(\left(A \beta_{1} \gamma_{2}\right) /\left(4 \beta_{1} \beta_{2}-\gamma_{1} \gamma_{2}\right)\right)$. Since $\beta_{2}>\gamma_{2}$, $\left|\frac{\partial r_{1}}{\partial d}\right|$ is greater than $\left|\frac{\partial r_{2}}{\partial d}\right|$. This proves that $r_{1}$ decreases at a faster rate in comparison to $r_{2}$ with $d$.

Section 4.1.2 outlines that retailer i declines its retail cost if the manufacturer gives a substantial cash discount to retailer i. Subsequently, retailer $j$ also reduces its retail cost as its competitor retailer i reduces its retail price. However, a decrease in the retail price is more 
in the case of retailer $i$ as compared to retailer $j$. This happens because the manufacturer provides a cash discount to retailer $i$ instead of retailer $j$. Moreover, both retailers $i$ and $j$ reduce their retail prices if the manufacturer grants a longer credit period to the retailer $j$. Nonetheless, the reduction in the retail price of retailer $j$ is more in comparison to retailer $i$. This occurs because the credit period is given to retailer $j$ instead of retailer $i$ by the manufacturer.

\subsubsection{Proposition}

(a) For a given $d, N_{j}$ increases as the $p$ increases.

(b) For a given $p, N_{i}$ increases as the $d$ increases.

\section{Proof}

(a) Since $\frac{\partial N_{j}}{\partial p}=\left(2 A k \beta_{1} \beta_{2}^{2}\right) /\left(4 \beta_{1} \beta_{2}-\gamma_{1} \gamma_{2}\right)-\left(A k \beta_{2} \gamma_{1} \gamma_{2}\right) /\left(4 \beta_{1} \beta_{2}-\gamma_{1} \gamma_{2}\right)$ and $\beta_{1} \beta_{2}>$ $\gamma_{1} \gamma_{2}, N_{j}$ increases as the $p$ increases.

(b) Since $\frac{\partial N_{i}}{\partial d}=\left(2 A \beta_{1}^{2} \beta_{2}\right) /\left(4 \beta_{1} \beta_{2}-\gamma_{1} \gamma_{2}\right)-\left(A \beta_{1} \gamma_{1} \gamma_{2}\right) /\left(4 \beta_{1} \beta_{2}-\gamma_{1} \gamma_{2}\right)$ and $\beta_{1} \beta_{2}>$ $\gamma_{1} \gamma_{2}$, Ni increases as the $d$ increases.

Section 4.1.3 describes that retailer i orders a greater quantity if the manufacturer provides a higher cash discount to retailer $i$, whereas retailer $j$ orders a greater quantity if the manufacturer offers a more extended credit period to retailer $j$.

\subsection{Decision of the Collector}

In the proposed remanufacturing system, the third party assumes the liability in the interest of the manufacturer to gather the end-of-life (EOL) and end-of-use (EOU) products from the market. The third party gathers these items from the market at a specific fixed value $X$ and gets unit fixed exchange cost $b$ from the manufacturer. Moreover, the third party makes the expenditure $l f^{2}$ in collecting the used products from the market.

The profit of the third party collector can be expressed as follows:

$$
\Pi_{t}=(b-X) f\left(N_{i}+N_{j}\right)-l f f
$$

Since $\frac{\partial^{2} \Pi_{t}}{\partial f^{2}}=-2 l$ and $l$ is a positive number, $\Pi_{t}$ is concave in nature. Hence, the optimum value of $\mathrm{f}$ is obtained by solving $\frac{\partial \Pi_{t}}{\partial f}=0$ as follows.

$$
f=\left((b-X)\left(\alpha_{1}+\alpha_{2}-r_{1} \beta_{1}-r_{2} \beta_{2}+r_{2} \gamma_{1}+r_{1} \gamma_{2}\right)\right) /(2 l)
$$

\subsection{Manufacturer's Problem}

After adopting the decisions of retailers' retail price and order quantity, the manufacturer determines the optimum credit period and cash discount to maximize his profit. The profit of the manufacturer through the sale of his products to both retailers can be expressed as follows:

Manufacturer's profit from the sale of products to retailer i:

$$
\Pi_{m i}=(A-m+f(n-b)) N_{i}-A d N_{i}
$$

Manufacturer's profit from the sale of products to retailer j:

$$
\Pi_{m j}=(A-m+f(n-b)) N_{j}-p A k N_{j}
$$

Manufacturer's total profit from the sale of products to both retailers i and j:

$$
\Pi_{m t}=\Pi_{m j}+\Pi_{m j}
$$


$\prod_{m} t$ is concave in nature (see Appendix A). Now, the optimum values of $d\left(d^{*}\right)$ and $p\left(p^{*}\right)$ are obtained by solving $\frac{\partial \Pi_{m t}}{\partial p}=0$ and $\frac{\partial \Pi_{m t}}{\partial d}=0$ simultaneously after substituting the optimum values of $r_{1}, r_{2}, \mathrm{~N}_{\mathrm{i}}, \mathrm{N}_{\mathrm{j}}$, and $f$ in the Equation (7). The expressions for $d^{*}$ and $p^{*}$ are shown in the Appendix A.

Further, total optimal profit of the chain $\Pi_{c t}^{*}$ is obtained using the following expression as follows.

$$
\Pi_{c t}^{*}=\Pi_{m t}^{*}+\Pi_{i}^{*}+\Pi_{j}^{*}+\Pi_{t}^{*}
$$

\section{Numerical Study}

Here, the authors have presented a numerical example to get insight into the decisions of retailers and the manufacturer. This numerical study explains the profit of both retailers and the manufacturer, decisions of the manufacturer on optimal credit period and cash discount, decisions of the retailers on their retail prices and order quantity, and decisions of the third-party collector in the CLSC. In this paper, we consider the following parameters: announced wholesale price $A=80$, cost of manufacturing $m=30$, the difference in manufacturing and remanufacturing $\cos t n=20$, transfer price $b=10$, the amount paid to customers $X=5$, capital opportunity cost $k=0.1$, scaling parameter $l=500, \alpha_{1}=40, \alpha_{2}=30$, $\beta_{1}=1, \beta_{2}=1, \gamma_{1}=1$ and $\gamma_{2}=1$.

Table 2 represents the results obtained after substituting the above-mentioned parameters in the proposed models. The findings show that optimal credit period $p^{*}$ given to retailer $i$ is equal to 1.145 and optimal cash discount $d^{*}$ given to retailer $j$ is equal to 0.077 . Whereas the profit of the manufacturer $\Pi_{m t}^{*}$ is equal to 889.86 . The retailer $i^{\prime}$ s retail price $r_{1}^{*}=84.94$, ordering quantity $N_{i}^{*}=11.16$, and the profit $\Pi_{i}^{*}=124.59$. On the other hand, the retailer $j^{\prime}$ 's retail price $r_{2}{ }^{*}=80.14$, the order quantity $N_{j}{ }^{*}=9.31$, and total profit $\Pi_{j}^{*}=86.68$. The fraction of the products collected by the third party $f^{*}=0.10$ and its profit $\Pi_{t}^{*}=5.25$. Moreover, the total profit of the non-coordinated system $\Pi_{c t}^{*}$ is equal to 1101.13.

Table 2. Numerical study.

\begin{tabular}{cccccccccccc}
\hline & $p^{*}$ & $d^{*}$ & $\Pi_{m t}^{*}$ & $r_{1}{ }^{*}$ & $N_{i}{ }^{*}$ & $\Pi_{i}^{*}$ & $r_{2}{ }^{*}$ & $N_{j}{ }^{*}$ & $\Pi_{j}^{*}$ & $f^{*}$ & $\Pi_{t}^{*}$ \\
\hline$m_{r}$ & 1.14 & 0.07 & 889.86 & - & - & - & - & - & - & - \\
$i$ & - & - & - & 84.94 & 11.16 & 124.59 & - & - & - & - \\
$j$ & - & - & - & - & - & - & 80.14 & 9.31 & 86.68 & - \\
$t$ & - & - & - & - & - & - & - & - & - & 0.10 & 5.25 \\
\hline
\end{tabular}

* represents the optimum value.

\section{Sensitivity Analysis}

In this section, the authors have demonstrated the influence of market size $(\alpha)$, price elasticity $(\beta)$ and cross-price elasticity $(\gamma)$ on the retailer $i^{\prime}$ s profit $\Pi_{i}^{*}$, retailer j's profit $\Pi_{j}^{*}$, and manufacturer's total profit $\Pi_{m t}^{*}$. Moreover, the influence of price elasticity $\beta$ and cross-price elasticity $\gamma$ is also investigated on the optimal credit period $p$ and cash discount $d$.

\subsection{Effect of the Market Size ( $\alpha$ )}

The influence of market size $(\alpha)$ on the profit of both the retailer and manufacturer is represented in Figure 3. It is observed that the profit of both retailers increases marginally with the increase in market size. However, the profit of the manufacturer rises significantly with the rise in the market size. At a particular value of $(\alpha)$, the profit of the manufacturer is the highest and the profit of both the retailer is nearly equal. 


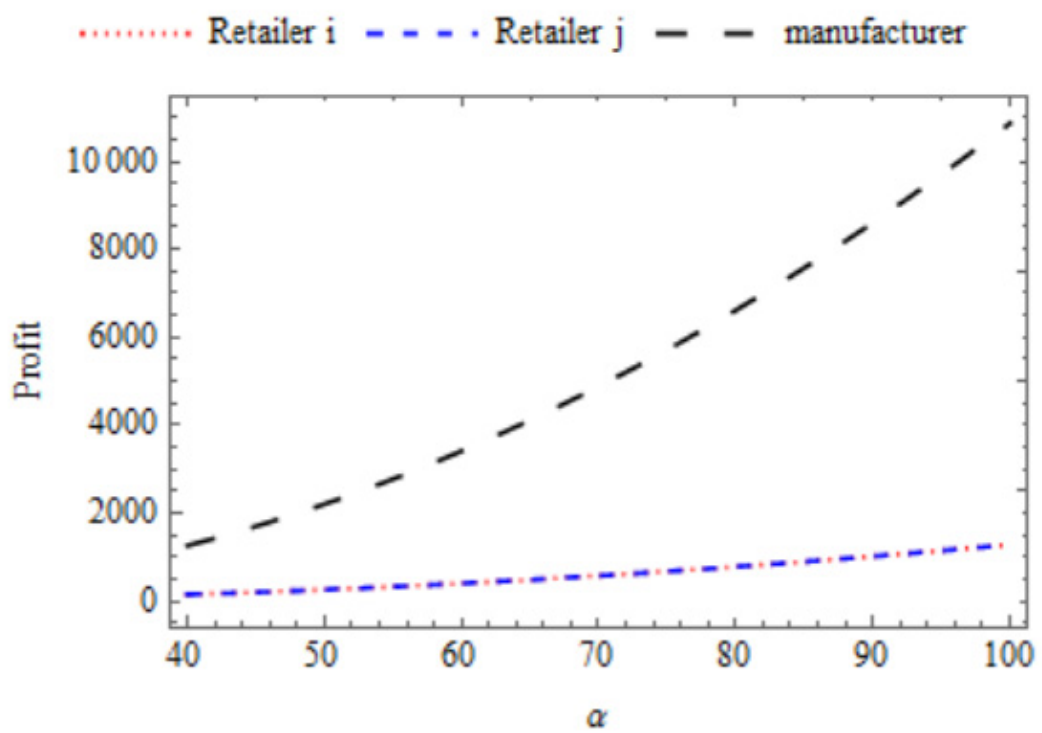

Figure 3. Impact of the market size $(\alpha)$.

\subsection{Effect of Price Elasticity ( $\beta$ )}

Here, the authors investigate the influence of $\beta$ on the profit of three players of CLSC that is retailer $i$, retailer $j$, and manufacturer. Figure 4 shows that the profit of the manufacturer decreases significantly with the enhancement in $\beta$, whereas the profit of both the retailer decreases marginally with the rise in the value of $\beta$. However, at a particular value of $\beta$, the profit of the manufacturer is highest, and the profit of retailer i is marginally higher than the profit of retailer $\mathrm{j}$. Moreover, Table 3 also indicates that the profit of each member decreases with the rise in the price elasticity. However, credit period $p$ and cash discount $d$ increase with the increase in the price elasticity. This signifies that the manufacturer must grant a prolonged credit period and a substantial cash discount when the demand possesses more sensitivity towards the retail price.

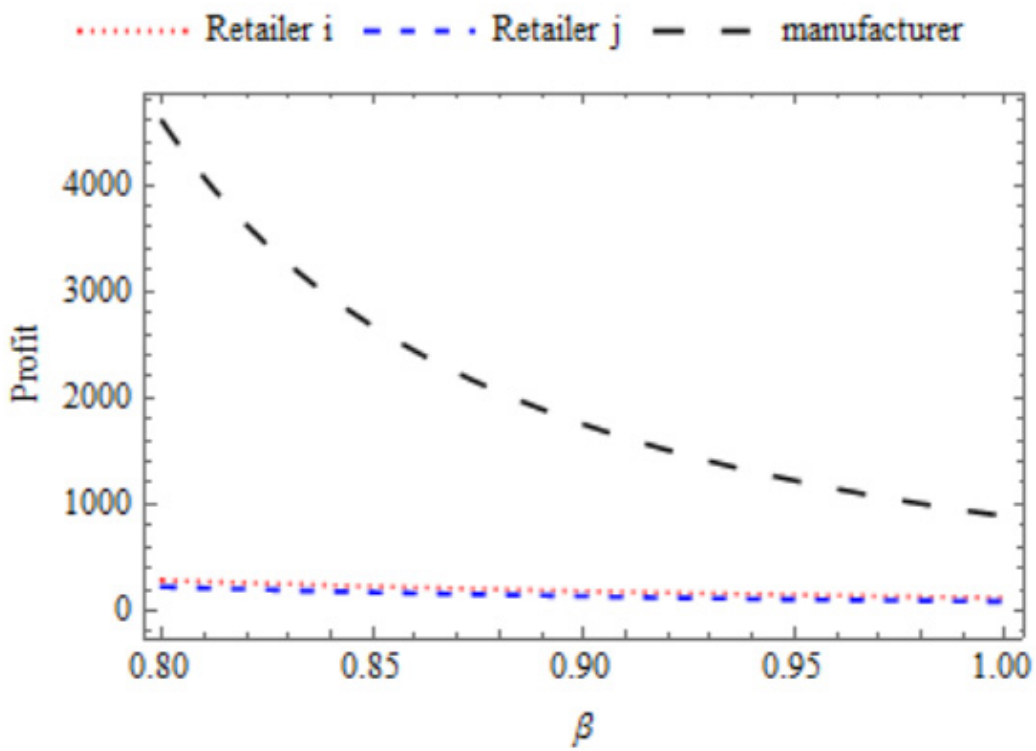

Figure 4. Impact of price elasticity $(\beta)$. 
Table 3. Impact of price elasticity $\beta$.

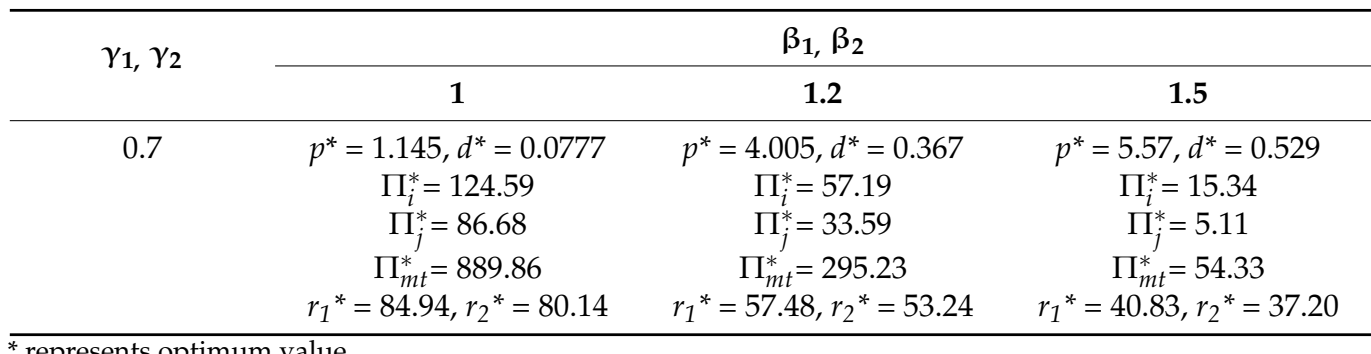

\subsection{Effect of Cross-Price Elasticity $(\gamma)$}

The effect of cross-price elasticity $\gamma$ on the profit of retailer $i, j$, and manufacturer is depicted in Figure 5. It is observed that the profit of all the three members of CLSC increases with the increase in $\gamma$. However, the rise in the profit of the manufacturer is significantly more than the profit of both retailers. At a particular value of $\gamma$, the profit of the manufacturer is highest followed by retailer $i$ and retailer $j$. Moreover, Table 4 also signifies that the profit of each member increases with the rise in the cross-price elasticity $\gamma$. However, cash discount $d$ and credit period $p$ decrease with the rise in the $\gamma$. This implies that the manufacturer can give less cash discount and a shorter period for a credit to the retailers in the case of the higher sensitivity of the demand towards the competition between the retailers.

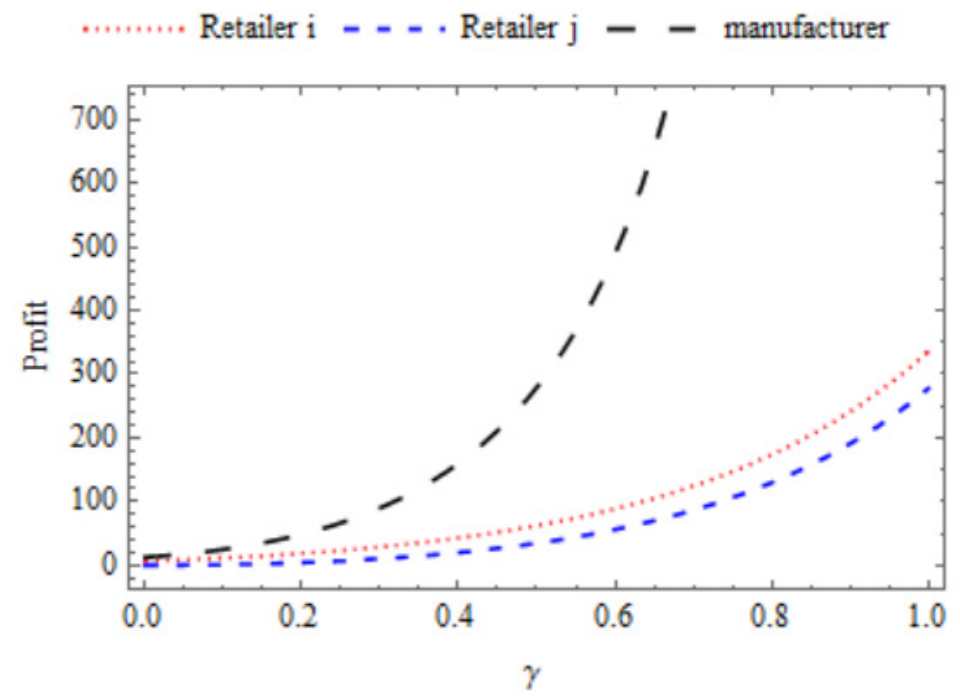

Figure 5. Impact of cross-price elasticity $(\gamma)$.

Table 4. Impact of cross-price elasticity $\gamma$.

\begin{tabular}{|c|c|c|c|}
\hline \multirow{2}{*}{$\beta_{1}, \beta_{2}$} & \multicolumn{3}{|c|}{$\gamma_{1}, \gamma_{2}$} \\
\hline & 0.3 & 0.5 & 0.7 \\
\hline 1 & $\begin{array}{c}\mathrm{p}^{*}=5.294, \mathrm{~d}^{*}=0.48 \\
\Pi_{i}^{*}=28.95 \\
\Pi_{j}^{*}=10.28\end{array}$ & $\begin{array}{c}\mathrm{p}^{*}=4.044, \mathrm{~d}^{*}=0.362 \\
\Pi_{i}^{*}=62.35 \\
\Pi_{j}^{*}=34.76\end{array}$ & $\begin{array}{c}\mathrm{p}^{*}=1.145, \mathrm{~d}^{*}=0.0777 \\
\Pi_{i}^{*}=124.59 \\
\Pi_{j}^{*}=86.68\end{array}$ \\
\hline & $\begin{array}{c}\Pi_{m t}^{*}=90.07 \\
\mathrm{r}_{1}^{*}=46.87, \mathrm{r}_{2}^{*}=40.85\end{array}$ & $\begin{array}{c}\Pi_{m t}^{*}=279.19 \\
\mathrm{r}_{1}^{*}=58.87, \mathrm{r}_{2}^{*}=53.54\end{array}$ & $\begin{array}{c}\Pi_{m t}^{*}=889.86 \\
\mathrm{r}_{1}^{*}=84.94, \mathrm{r}_{2}^{*}=80.14\end{array}$ \\
\hline
\end{tabular}

${ }^{*}$ represents optimum value.

\section{Coordination Strategy in the Dual-Retailer Closed-Loop Supply Chain}

In Section 4, the authors have developed mathematical models for the decentralized system where each member of the chain takes the decision independently to maximize 
their profits. However, manufacturer, retailer i, retailer $\mathrm{j}$, and the third party can also ally and determine their decisions to maximize the profit of the total chain. Gan et al. [69] and Wang et al. [61] illustrated that all the members of the chain work cohesively in order to maximize the profit of the entire chain instead of individual profit in a coordinated system. Here, the authors have developed the mathematical models for the coordinated system in which each member is committed to maximizing the profit of the chain. The total profit of the chain in the coordinated system $\Pi_{c c t}$ can be written as follows:

$$
\Pi_{c c t}=\Pi_{m t}+\Pi_{i}+\Pi_{j}+\Pi_{t}
$$

where Equations (1), (2), (5) and (7) represent the $\Pi_{i}, \Pi_{j}, \Pi_{t}$, and $\Pi_{m t}$, respectively. It is observed that Equation (8) is independent of $\mathrm{d}, \mathrm{p}$, and A due to the coordinated system.

Since $\Pi_{c c t}$ is concave in $f, r_{1}$, and $r_{2}$ (see Appendix B), we obtain the optimal values of $f, r_{1}, r_{2}$ by the simultaneous solution of $\frac{\partial \prod_{c c t}}{\partial f}=0, \frac{\partial \prod_{c c t}}{\partial r_{1}}=0$ and $\frac{\partial \prod_{c c t}}{\partial r_{2}}=0$. The optimum solutions for $f\left(f^{*}\right) r_{1}\left(r_{1}{ }^{*}\right)$ and $r_{2}\left(r_{2}{ }^{*}\right)$ are shown in Appendix B. After substituting the optimum values of $f, r_{1}$, and $r_{2}$ into the expressions of $\Pi_{i}, \Pi_{j}, \Pi_{m t}$, and $\Pi_{t}$, the optimal profit of chain can be written as follows:

$$
\Pi_{c c t}^{*}=\Pi_{m t}^{*}+\Pi_{i}^{*}+\Pi_{j}^{*}+\Pi_{t}^{*}
$$

Further, in order to get insights into the coordinated system, the authors have substituted the numerical values, as mentioned in Section 5 , into the proposed coordinated model. The results of this analysis represent that $\Pi_{c c t}^{*}=1251, \mathrm{f}^{*}=0.418, \mathrm{r} 1^{*}=71.66, \mathrm{r} 2^{*}=68.72$. Thus, the total chain profit and collection rate is more in the case of a coordinated system as compared to a non-coordinated system. This implies that total chain profit increases due to the coordination among the members of CLSC. In addition, there is a substantial increase in the collection of used products as the value of $\mathrm{f}$ enhances. The rise in the value of $f$ creates a positive effect on the environment by shrinking the consumption of raw material and diminishing the need for land-filling of used products. Thus, the collection of the waste required to bring circularity in the production increases. It helps in achieving the objectives of industrial ecology. Awan et al. [70] also suggested the need for closedloop industrial production and consumption system for attaining sustainability through industrial ecology. However, the collection of waste in developing countries such as India is one of the major hindrances to the closure of the material loop and hence to achieve sustainable development goals. For that, firms must adopt a centralized decision-making system to increase the benefits to the entire CLSC and industrial ecosystem. The findings also reveal that both the retailers reduce their retail prices in the coordinated system. Thus, the adoption of a coordinated strategy by the members of CLSC provides both economic and environmental benefits.

\section{Conclusions}

Ecological footprints of economic production and consumption can be diminished by closing the material and resource loop through the adoption of CE practices. Some circular business models have encountered quick development as of late, largely because of the rise of new advances [1,27]. The development of circular business models will help in attaining the objectives of industrial ecology [70]. Therefore, this study contemplates a dual-retailer closed-loop supply chain (CLSC) comprising one manufacturer and two retailers. Used products are collected by the third party from the market and supplied to the manufacturer at the transfer price $b$. Here, the manufacturer furnishes a credit period $p$ to the one retailer and cash discount $d$ to the other retailer in order to enhance the sale of its products. Demand for an item diminishes with its own retail cost and increases with the contender's retail cost. This paper aims to evaluate the optimal cash discount $d$ and credit period $p$ provided by the supplier to maximize its profit. Furthermore, this paper determines the optimal order quantity and retail price of the retailers to maximize their profit in the CLSC. The authors have considered the optimization properties and 
proposition-based solution approach to answer this problem. Moreover, numerical analysis and sensitivity analysis is performed to achieve insights into the optimal decisions of the manufacturer and retailers. Further, the authors have evaluated the impact of coordination strategy on the decision variables of dual-retailer CLSC.

This research makes a unique contribution to the body of literature on CLSC and remanufacturing by examining the manufacturer's incentive in the dual-retailer CLSC under price competition. Two of the most popular incentive strategies such as credit period and cash discount are analyzed. The authors have developed mathematical models to compute the optimal selling price and ordering quantity of the retailers and to estimate the optimal credit period and cash discount given by the manufacturer to the retailers. Further, the results of the sensitivity analysis show that the profit of the retailer $i$, retailer $j$, and manufacturer increases with the augmentation in the market size $\alpha$ and cross-price elasticity $\gamma$, and decreases with growth in the price elasticity $\beta$. In addition, it is also observed that the credit period and cash discount increases with the rise in price elasticity, and decreases with an increase in the cross-price elasticity. The findings also suggest that a retailer obtains large quantities and reduces the retail price to a greater extent if the manufacturer gives more incentive to the retailer. It is also observed that total chain profit increases due to the coordination among the members of CLSC. Furthermore, it is found that if the members of this chain work in coordination, there is a substantial increase in the collection of used products as the value of $f$ enhances. Moreover, the rise in the collection of waste signifies the importance of coordination among the CLSC members needed to meet the sustainable development goals. Hence, this research developed the mathematical models to understand the practical problem of the manufacturer's incentive in the context of multiple retailers in CLSC, and evaluated the impact of coordinated strategy on the environmental and economical front. Thus, the findings of the paper will assist firms operating in a closed-loop environment in understanding the optimal decision variables and optimal profits under the manufacture's incentive scenario. The paper will also provide insights to decision makers regarding centralized and decentralized decision making in CLSC under the manufacture's incentive scenario. Awan et al. [10] explained that industry 4.0 innovations may help the firms in supporting the $\mathrm{CE}$ initiatives. Therefore, the proposed study framework of the paper may be used by the researchers in exploring the impact of industry 4.0 technologies in circular business models.

\section{Limitations and Future Work}

Like all research, this study also possesses a few limitations. However, these limitations provide the direction for future research. Here, the demand for the product is presumed to be linear and non-probabilistic. Further, the analysis can be done by considering the uncertain and non-linear nature of demand. Zhen et al. [71] suggested using the simulation approach for handling the stochastic variables in SC models. Moreover, the study examines non-differentiated remanufactured and new products such as cameras and Xerox machines. In the future, analysis can be done for a scenario in which firms differentiate between remanufactured and brand-new products. Sun et al. [72] illustrated the concept of differentiation competition in remanufacturing. Further, the proposed framework can be used under both price and service competition because buying decisions are also influenced by services besides pricing. In addition, the authors recommend investigating the combined impact of a manufacture's incentive, digital efforts, and sustainability efforts in the supply chain under different power balance structures.

Author Contributions: Conceptualization, D.S. and S.T.; methodology, D.S. and S.K.J.; validation, S.A., S.T. and H.-C.K.; formal analysis, S.A., S.K.J., D.S. and S.T.; data curation, D.S. and S.T.; writingoriginal draft preparation, D.S., S.K.J. and S.T.; writing-review and editing, S.A. and S.T.; supervision, H.-C.K.; project administration, H.-C.K.; funding acquisition, H.-C.K. All authors have read and agreed to the published version of the manuscript. 
Funding: This work was supported by the Commercializations Promotion Agency for R\&D Outcomes (COMPA) grant funded by the Korean Government (Ministry of Science and ICT)" (R\&D project No.1711139492).

Informed Consent Statement: All the participants gave their consent to participate in this study.

Conflicts of Interest: The authors declare no conflict of interest.

\section{Appendix A}

$$
\begin{aligned}
& \Pi_{m i}=(A-m+f(n-b)) N_{i}-A d N_{i} \\
& \Pi_{m j}=(A-m+f(n-b)) N_{j}-p A k N_{j} \\
& \Pi_{m t}=\Pi_{m j}+\Pi_{m j} \\
& H(d, p)=\left[\begin{array}{cc}
\frac{\partial^{2} \Pi_{m t}}{\partial^{2} d} & \frac{\partial^{2} \Pi_{m t}}{\partial d \partial p} \\
\frac{\partial^{2} \Pi_{m t}}{\partial p \partial d} & \frac{\partial^{2} \Pi_{m t}}{\partial^{2} p}
\end{array}\right]
\end{aligned}
$$

Since $H(d, p)>0$ and principal diagonals are negative, the objective function $\left(\Pi_{m t}\right)$ is concave in nature.

The optimum values of $d\left(d^{*}\right)$ and $p\left(p^{*}\right)$ are obtained and written as follows: $d *=\frac{d_{n}}{d_{d}}$ and $p *=\frac{p_{n}}{p_{d}}$ where $\mathrm{d}_{\mathrm{n}}, \mathrm{d}_{\mathrm{d}}, \mathrm{p}_{\mathrm{n}}, \mathrm{p}_{\mathrm{d}}$ are defined as follows:

$$
d_{n}=\left[\begin{array}{l}
\left(4 A(b-n)(b-X) \beta_{1}^{2} \beta_{2}^{2}+\gamma_{1} \gamma_{2}\left(\left(\operatorname{lm} \beta_{2}+\alpha_{2}\left(2 l+(b-n)(b-X) \beta_{2}\right)\right) \gamma_{1}\right.\right. \\
\left.-\left(2 l(-2 A+m) \gamma_{1}+\beta_{2}\left(l m-2 A(b-n)(b-X) \gamma_{1}\right)\right) \gamma_{2}\right)+ \\
\alpha_{1} \beta_{2}\left(\beta_{1} \beta_{2}\left(-8 l-(b-n)(b-X)\left(4 \beta_{1}+2 \beta_{2}-\gamma_{1}\right)\right)+\left(3 l+(b-n)(b-X)\left(3 \beta_{1}+\beta_{2}\right)\right) \gamma_{1} \gamma_{2}\right. \\
\left.-\left(l-(b-n)(b-X) \gamma_{1}\right)\right) \gamma_{2}{ }^{2}+\beta_{1}\left(\beta _ { 2 } \gamma _ { 1 } \left(-2 \operatorname{lm} \beta_{2}+\alpha_{2}\left(-6 l-(b-n)(b-X)\left(2 \beta_{2}-\gamma_{1}\right)\right)+\right.\right. \\
\left.l(-A+m) \gamma_{1}\right)+\left(2 l \beta_{2}\left(-\alpha_{2}+m \beta_{2}\right)+3 \beta_{2}\left(3 l(-2 A+m)+(b-n)(b-X)\left(\alpha_{2}-2 A \beta_{2}\right)\right) \gamma_{1}\right. \\
\left.+2(b-n)(b-X)\left(\alpha_{2}+A \beta_{2}\right) \gamma_{1}^{2}\right) \gamma_{2}-A\left(-2(b-n)(b-X) \gamma_{1}^{2}+\right. \\
\left.\left.\beta_{2}\left(l-2(b-n)(b-X) \gamma_{1}\right)\right) \gamma_{2}^{2}\right)
\end{array}\right]
$$$$
d_{d}=\left[\begin{array}{l}
\left(A \left(4(b-n)(b-X) \beta_{1}^{2} \beta_{2}^{2}+2\left(2 l+(b-n)(b-X) \beta_{2}\right) \gamma_{1}{ }^{2} \gamma_{2}{ }^{2}+\right.\right. \\
2 \beta_{1}^{2} \beta_{2}\left(\beta_{2}\left(8 l+(b-n)(b-X)\left(2 \beta_{2}-\gamma_{1}\right)\right)-(b-n)(b-X)\left(\beta_{2}+3 \gamma_{1}\right) \gamma_{2}\right)+ \\
\beta_{1}\left(-l \beta_{2} \gamma_{1}{ }^{2}-2 \beta_{2}\left(9 l+(b-n)(b-X)\left(3 \beta_{2}-\gamma_{1}\right)\right) \gamma_{1} \gamma_{2}-\left(-2(b-n)(b-X) \gamma_{1}{ }^{2}+\right.\right. \\
\left.\left.\left.\left.\beta_{2}\left(l-2(b-n)(b-X) \gamma_{1}\right)\right) \gamma_{2}^{2}\right)\right)\right)
\end{array}\right]
$$$$
\begin{aligned}
& p_{n}= {\left[\begin{array}{l}
\left(4 A(b-n)(b-X)+2 \gamma_{1}\left(\alpha_{1}\left(l+(b-n)(b-X) \beta_{2}\right)+\right.\right. \\
\left.\left(l(2 A-m)+A(b-n)(b-X) \beta_{2}\right) \gamma_{1}\right)+\beta_{1}\left(-l \beta_{2} \gamma_{1}\left(2 \alpha_{1}+A \gamma_{1}\right)-\right. \\
\left(3 \alpha_{1} \beta_{2}\left(2 l+(b-n)(b-X)\left(\beta_{2}-\gamma_{1}\right)\right)+\gamma_{1}\left(9 l(2 A-m) \beta_{2}+6 A(b-n)(b-X)+\right.\right. \\
\left.\left.\left(l m-2 A(b-n)(b-X) \beta_{2}\right) \gamma_{1}\right)\right) \gamma_{2}+\left(\gamma_{1}\left(l m+(b-n)(b-X)\left(\alpha_{1}+2 A \gamma_{1}\right)\right)+\right. \\
\left.\beta_{2}\left(l(-A+m)+(b-n)(b-X)\left(\alpha_{1}+2 A \gamma_{1}\right)\right)\right)-\alpha_{2} \beta_{1}\left(2(b-n)(b-X) \beta_{2}+\right. \\
\beta_{1}\left(4 \beta_{2}\left(2 l+(b-n)(b-X) \beta_{2}\right)-(b-n)(b-X)\left(\beta_{2}+\gamma_{1}\right) \gamma_{2}\right)+ \\
\left.\gamma_{1}\left(l \gamma_{1}+\left(-3 l-(b-n)(b-X)\left(3 \beta_{2}+\gamma_{1}\right)\right) \gamma_{2}\right)\right)+2 \beta_{2}(2 A(b-n)(b-X)+ \\
l m \gamma_{1}-\left(l m+(b-n)(b-X)\left(\alpha_{1}+3 A \gamma_{1}\right)\right) \gamma_{2}+ \\
\left.\beta_{2}\left(8 A l-4 l m-(b-n)(b-X)\left(\alpha_{1}+A\left(\gamma_{1}+\gamma_{2}\right)\right)\right)\right)
\end{array}\right] } \\
& p_{d}=\left[\begin{array}{l}
\left(A k \left(4(b-n)(b-X)+2\left(2 l+(b-n)(b-X) \beta_{2}\right)+\right.\right. \\
2 \beta_{2}\left(\beta_{2}\left(8 l+(b-n)(b-X)\left(2 \beta_{2}-\gamma_{1}\right)\right)-(b-n)(b-X)\left(\beta_{2}+3 \gamma_{1}\right) \gamma_{2}\right)+ \\
\beta_{1}\left(-l \beta_{2}-2 \beta_{2}\left(9 l+(b-n)(b-X)\left(3 \beta_{2}-\gamma_{1}\right)\right) \gamma_{1} \gamma_{2}-(-2(b-n)(b-X)+\right. \\
\left.\left.\left.\beta_{2}\left(l-2(b-n)(b-X) \gamma_{1}\right)\right)\right)\right)
\end{array}\right]
\end{aligned}
$$

\section{Appendix B}

$$
\Pi_{c c t}=\Pi_{m t}+\Pi_{i}+\Pi_{j}+\Pi_{t}
$$




$$
H(f, d, p)=\left[\begin{array}{lll}
\frac{\partial^{2} \Pi_{c c t}}{\partial^{2} f} & \frac{\partial^{2} \Pi_{c c t}}{\partial f \partial d} & \frac{\partial^{2} \Pi_{c c t}}{\partial f \partial p} \\
\frac{\partial^{2} \Pi_{c c t}}{\partial d \partial f} & \frac{\partial^{2} \Pi_{c c t}}{\partial^{2} d} & \frac{\partial^{2} \Pi_{c c t}}{\partial d p} \\
\frac{\partial^{2} \Pi_{c c t}}{\partial p \partial f} & \frac{\partial^{2} \Pi_{c c t}}{\partial p \partial d} & \frac{\partial^{2} \Pi_{c c t}}{\partial^{2} p}
\end{array}\right]
$$

Since $H(f, d, p)>0$ and principal diagonals are negative, the objective function $\left(\Pi_{c c t}\right)$ is concave in nature.

Further, the optimum values of $f, r_{1}$, and $r_{2}$ are obtained as follows:

$$
f=\left((n-X)\left(\alpha_{1}+\alpha_{2}+r_{2}\left(-\beta_{2}+\gamma_{1}\right)+r_{1}\left(-\beta_{1}+\gamma_{2}\right)\right)\right) /(2 l)
$$

$\mathrm{r}_{1}{ }^{*}=(\mathrm{A}+\mathrm{B}+\mathrm{C}+\mathrm{D}) /(\mathrm{E}-\mathrm{F})$, where $\mathrm{A}, \mathrm{B}, \mathrm{C}, \mathrm{D}, \mathrm{E}$, and $\mathrm{F}$ represent the following terms:

$$
\begin{aligned}
A & =\left(\alpha_{2}\left(2 l-(n-X)^{2}\left(\beta_{2}-\gamma_{1}\right)\right)+2 \operatorname{lm}\left(\beta_{2}-\gamma_{1}\right)\right) \gamma_{1} \\
B & =\beta_{1}\left(\left(4 l m-(n-X)^{2} \alpha_{2}\right) \beta_{2}-(n-X)^{2} \alpha_{2} \gamma_{1}\right) \\
C & =2\left(-\operatorname{lm}\left(\beta_{2}+\gamma_{1}\right)+\alpha_{2}\left(l+(n-X)^{2} \gamma_{1}\right)\right) \gamma_{2} \\
D & =\alpha_{1}\left(\beta_{2}\left(4 l-(n-X)^{2}\left(2 \beta_{1}+\beta_{2}-\gamma_{1}\right)\right)+(n-X)^{2}\left(\beta_{2}+\gamma_{1}\right) \gamma_{2}\right) \\
E & =2\left(-(n-X)^{2} \beta_{2}-l+\left(-2 l+(n-X)^{2}\left(\beta_{2}-\gamma_{1}\right)\right) \gamma_{1} \gamma_{2}\right. \\
& \left.F=\left(l+(n-X)^{2} \gamma_{1}\right)+\beta_{1}\left(\beta_{2}\left(4 l-(n-X)^{2}\left(\beta_{2}-\gamma_{1}\right)\right)+(n-X)^{2}\left(\beta_{2}+\gamma_{1}\right) \gamma_{2}\right)\right) \\
& \mathrm{r}_{2}{ }^{*}=(\mathrm{G}+\mathrm{H}+\mathrm{I}) /(\mathrm{J}-\mathrm{K}), \text { where G, H, I, J and K represent the following terms: } \\
G= & 4 l m \beta_{1} \beta_{2}-n^{2} \alpha_{1} \beta_{1} \beta_{2}+2 n X \alpha_{1} \beta_{1} \beta_{2}-X^{2} \alpha_{1} \beta_{1} \beta_{2}+2 l \alpha_{1} \gamma_{1}-2 \operatorname{lm} \beta_{1} \gamma_{1} \\
H= & \left(\alpha_{1}\left(2 l-(n-X)^{2}\left(\beta_{1}+\beta_{2}-2 \gamma_{1}\right)\right)+2 l m\left(\beta_{1}-\gamma_{1}\right)\right) \gamma_{2}+\left(-2 l m+(n-X)^{2} \alpha_{1}\right) \gamma_{2}{ }^{2} \\
I= & \alpha_{2}\left(\beta_{1}\left(4 l-(n-X)^{2}\left(\beta_{1}+2 \beta_{2}-\gamma_{1}\right)\right)+(n-X)^{2}\left(\beta_{1}+\gamma_{1}\right) \gamma_{2}\right) \\
J= & 2\left(-(n-X)^{2} \beta_{2}-l+\left(-2 l+(n-X)^{2}\left(\beta_{2}-\gamma_{1}\right)\right) \gamma_{1} \gamma_{2}-\left(l+(n-X)^{2} \gamma_{1}\right) \gamma_{2}{ }^{2}\right. \\
K= & \left.\beta_{1}\left(\beta_{2}\left(4 l-(n-X)^{2}\left(\beta_{2}-\gamma_{1}\right)\right)+(n-X)^{2}\left(\beta_{2}+\gamma_{1}\right) \gamma_{2}\right)\right)
\end{aligned}
$$

\section{References}

1. Ferasso, M.; Beliaeva, T.; Kraus, S.; Clauss, T.; Ribeiro-Soriano, D. Circular economy business models: The state of research and avenues ahead. Bus. Strategy Environ. 2020, 29, 3006-3024. [CrossRef]

2. Chauhan, A.; Jakhar, S.K.; Chauhan, C. The Interplay of Circular Economy with Industry 4.0 Enabled Smart City Drivers of Healthcare Waste Disposal. J. Clean. Prod. 2021, 279, 123854. [CrossRef] [PubMed]

3. Kirchherr, J.; Reike, D.; Hekkert, M. Conceptualizing the circular economy: An analysis of 114 definitions. Resour. Conserv. Recycl. 2017, 127, 221-232. [CrossRef]

4. Hazen, B.T.; Mollenkopf, D.A.; Wang, Y. Remanufacturing for the Circular Economy: An Examination of Consumer Switching Behavior: Remanufacturing Circular Economy Consumer Switching Behaviour. Bus. Strat. Environ. 2017, 26, 451-464. [CrossRef]

5. Subramanian, R.; Subramanyam, R. Key Factors in the Market for Remanufactured Products. Manuf. Serv. Oper. Manag. 2012, 14, 315-326. [CrossRef]

6. Milios, L.; Matsumoto, M. Consumer Perception of Remanufactured Automotive Parts and Policy Implications for Transi-tioning to a Circular Economy in Sweden. Sustainability 2019, 11, 6264. [CrossRef]

7. Jiang, Z.; Ding, Z.; Zhang, H.; Cai, W.; Liu, Y. Data-driven ecological performance evaluation for remanufacturing process. Energy Convers. Manag. 2019, 198, 111844. [CrossRef]

8. Chakraborty, K.; Mondal, S.; Mukherjee, K. Critical Analysis of Enablers and Barriers in Extension of Useful Life of Auto-motive Products through Remanufacturing. J. Clean. Prod. 2019, 227, 1117-1135. [CrossRef]

9. Khor, K.S.; Hazen, B. Remanufactured products purchase intentions and behaviour: Evidence from Malaysia. Int. J. Prod. Res. 2016, 55, 2149-2162. [CrossRef]

10. Awan, U.; Sroufe, R.; Shahbaz, M. Industry 4.0 and the circular economy: A literature review and recommendations for future research. Bus. Strat. Environ. 2021, 30, 2038-2060. [CrossRef]

11. Feng, H.; Li, J.; Zhao, D. Retailer's optimal replenishment and payment policies in the EPQ model under cash discount and two-level trade credit policy. Appl. Math. Model. 2013, 37, 3322-3339. [CrossRef]

12. Giri, B.C.; Sharma, S. Optimising an integrated production-inventory system under cash discount and retailer partial trade credit policy. Int. J. Syst. Sci. Oper. Logist. 2017, 6, 99-118. [CrossRef] 
13. Feng, L.; Skouri, K.; Wang, W.-C.; Teng, J.-T. Optimal Selling Price, Replenishment Cycle and Payment Time among Ad-vance, Cash, and Credit Payments from the Seller's Perspective. Ann. Oper. Res. 2020, 1-22. [CrossRef]

14. Tsao, Y.-C.; Sheen, G.-J. A multi-item supply chain with credit periods and weight freight cost discounts. Int. J. Prod. Econ. 2012, 135, 106-115. [CrossRef]

15. Kim, J.; Hwang, H.; Shinn, S. An Optimal Credit Policy to Increase Supplier's Profits with Price-Dependent Demand Func-tions. Prod. Plan. Control 1995, 6, 45-50. [CrossRef]

16. Shah, N.H.; Cárdenas-Barrón, L.E. Retailer's decision for ordering and credit policies for deteriorating items when a supplier offers order-linked credit period or cash discount. Appl. Math. Comput. 2015, 259, 569-578. [CrossRef]

17. Chung, K.-J.; Liao, J.-J.; Lin, S.-D.; Chuang, S.-T.; Srivastava, H.M. The Inventory Model for Deteriorating Items under Con-ditions Involving Cash Discount and Trade Credit. Mathematics 2019, 7, 596. [CrossRef]

18. He, P.; He, Y.; Xu, H. Channel Structure and Pricing in a Dual-Channel Closed-Loop Supply Chain with Government Sub-sidy. Int. J. Prod. Econ. 2019, 213, 108-123. [CrossRef]

19. Ruiz-Torres, A.J.; Mahmoodi, F.; Ohmori, S. Joint determination of supplier capacity and returner incentives in a closed-loop supply chain. J. Clean. Prod. 2019, 215, 1351-1361. [CrossRef]

20. Jena, S.K.; Sarmah, S.P.; Padhi, S.S. Impact of government incentive on price competition of closed-loop supply chain systems. INFOR Inf. Syst. Oper. Res. 2017, 56, 192-224. [CrossRef]

21. Hong, X.; Xu, L.; Du, P.; Wang, W. Joint advertising, pricing and collection decisions in a closed-loop supply chain. Int. J. Prod. Econ. 2015, 167, 12-22. [CrossRef]

22. Hosseini-Motlagh, S.-M.; Nouri-Harzvili, M.; Johari, M.; Sarker, B.R. Coordinating economic incentives, customer service and pricing decisions in a competitive closed-loop supply chain. J. Clean. Prod. 2020, 255, 120241. [CrossRef]

23. Genc, T.S.; De Giovanni, P. Optimal return and rebate mechanism in a closed-loop supply chain game. Eur. J. Oper. Res. 2018, 269, 661-681. [CrossRef]

24. Alhawari, O.; Awan, U.; Bhutta, M.K.S.; Ülkü, M.A. Insights from Circular Economy Literature: A Review of Extant Defini-tions and Unravelling Paths to Future Research. Sustainability 2021, 13, 859. [CrossRef]

25. Hartley, K.; van Santen, R.; Kirchherr, J. Policies for Transitioning towards a Circular Economy: Expectations from the Eu-ropean Union (EU). Resour. Conserv. Recycl. 2020, 155, 104634. [CrossRef]

26. Reike, D.; Vermeulen, W.J.V.; Witjes, S. The circular economy: New or Refurbished as CE 3.0?-Exploring Controversies in the Conceptualization of the Circular Economy through a Focus on History and Resource Value Retention Options. Resour. Conserv. Recycl. 2018, 135, 246-264. [CrossRef]

27. Chen, T.-L.; Kim, H.; Pan, S.-Y.; Tseng, P.-C.; Lin, Y.-P.; Chiang, P.-C. Implementation of green chemistry principles in circular economy system towards sustainable development goals: Challenges and perspectives. Sci. Total. Environ. 2020, 716, 136998. [CrossRef] [PubMed]

28. Reddy, K.N.; Kumar, A. Capacity Investment and Inventory Planning for a Hybrid Manufacturing-Remanufacturing Sys-tem in the Circular Economy. Int. J. Prod. Res. 2021, 59, 2450-2478. [CrossRef]

29. Wang, X.; Zhu, Y.; Sun, H.; Jia, F. Production decisions of new and remanufactured products: Implications for low carbon emission economy. J. Clean. Prod. 2018, 171, 1225-1243. [CrossRef]

30. Singhal, D.; Tripathy, S.; Jena, S. Remanufacturing for the circular economy: Study and evaluation of critical factors. Resour. Conserv. Recycl. 2020, 156, 104681. [CrossRef]

31. Zhang, T.; Chu, J.; Wang, X.; Liu, X.; Cui, P. Development pattern and enhancing system of automotive components remanufacturing industry in China. Resour. Conserv. Recycl. 2011, 55, 613-622. [CrossRef]

32. van der Laan, E.; Salomon, M. Production Planning and Inventory Control with Remanufacturing and Disposal. Eur. J. Oper. Res. 1997, 102, 264-278. [CrossRef]

33. Guide, V.R. Production planning and control for remanufacturing: Industry practice and research needs. J. Oper. Manag. 2000, 18, 467-483. [CrossRef]

34. Yang, C.-H.; Liu, H.-B.; Ji, P.; Ma, X. Optimal acquisition and remanufacturing policies for multi-product remanufacturing systems. J. Clean. Prod. 2016, 135, 1571-1579. [CrossRef]

35. Wei, J.; Zhao, J. Pricing decisions with retail competition in a fuzzy closed-loop supply chain. Expert Syst. Appl. 2011, 38, 11209-11216. [CrossRef]

36. Alqahtani, A.Y.; Gupta, S.M. Warranty as a marketing strategy for remanufactured products. J. Clean. Prod. 2017, 161, 1294-1307. [CrossRef]

37. Galbreth, M.R.; Blackburn, J.D. Optimal Acquisition and Sorting Policies for Remanufacturing. Prod. Oper. Manag. 2009, 15, 384-392. [CrossRef]

38. Savaskan, R.C.; Bhattacharya, S.; Van Wassenhove, L.N. Closed-Loop Supply Chain Models with Product Remanufacturing. Manag. Sci. 2004, 50, 239-252. [CrossRef]

39. Savaskan, R.C.; Van Wassenhove, L.N. Reverse Channel Design: The Case of Competing Retailers. Manag. Sci. 2006, 52, 1-14. [CrossRef]

40. Choi, D.-W.; Hwang, H.; Koh, S.-G. A generalized ordering and recovery policy for reusable items. Eur. J. Oper. Res. 2007, 182, 764-774. [CrossRef] 
41. Jena, S.; Sarmah, S. Price competition and co-operation in a duopoly closed-loop supply chain. Int. J. Prod. Econ. 2014, 156, 346-360. [CrossRef]

42. Mitra, S. Optimal pricing and core acquisition strategy for a hybrid manufacturing/remanufacturing system. Int. J. Prod. Res. 2015, 54, 1-18. [CrossRef]

43. $\mathrm{Wu}, \mathrm{C} .-\mathrm{H}$. Price and service competition between new and remanufactured products in a two-echelon supply chain. Int. J. Prod. Econ. 2012, 140, 496-507. [CrossRef]

44. Huang, Y.-F. Optimal retailer's ordering policies in the EOQ model under trade credit financing. J. Oper. Res. Soc. 2003, 54, 1011-1015. [CrossRef]

45. Karimabadi, K.; Arshadi-khamseh, A.; Naderi, B. Optimal Pricing and Remanufacturing Decisions for a Fuzzy Du-al-Channel Supply Chain. Int. J. Syst. Sci. Oper. Logist. 2020, 7, 248-261.

46. Goyal, S.K. Economic Order Quantity under Conditions of Permissible Delay in Payments. J. Oper. Res. Soc. 1985, $36,335$. [CrossRef]

47. Moriarty, R.T.; Moran, U. Managing hybrid marketing systems. Harv. Bus. Rev. 1990, 68, 146-155.

48. Chung, K. A Theorem on the Determination of Economic Order Quantity under Conditions of Permissible Delay in Pay-ments. Comput. Oper. Res. 1998, 25, 49-52. [CrossRef]

49. Abad, P.L.; Jaggi, C.K. A Joint Approach for Setting Unit Price and the Length of the Credit Period for a Seller When End Demand Is Price Sensitive. Int. J. Prod. Econ. 2003, 83, 115-122. [CrossRef]

50. Huang, Y.-F.; Chung, K.-J. Note: A note on the production and inventory systems taking account of time value. Prod. Plan. Control 2003, 14, 673-675. [CrossRef]

51. Huang, Y. A Closed-Loop Supply Chain with Trade-In Strategy under Retail Competition. Math. Probl. Eng. 2018, 2018, 1-16. [CrossRef]

52. Wallace, D.W.; Giese, J.L.; Johnson, J.L. Customer retailer loyalty in the context of multiple channel strategies. J. Retail. 2004, 80, 249-263. [CrossRef]

53. Cai, G.G.; Zhang, Z.G.; Zhang, M. Game theoretical perspectives on dual-channel supply chain competition with price discounts and pricing schemes. Int. J. Prod. Econ. 2009, 117, 80-96. [CrossRef]

54. Liu, B.; Zhang, R.; Xiao, M. Joint decision on production and pricing for online dual channel supply chain system. Appl. Math. Model. 2010, 34, 4208-4218. [CrossRef]

55. Mitra, S.; Webster, S. Competition in remanufacturing and the effects of government subsidies. Int. J. Prod. Econ. 2008, 111, 287-298. [CrossRef]

56. Tsao, Y.-C. Managing a retail-competition distribution channel with incentive policies. Appl. Math. Model. 2011, 35, 4140-4148. [CrossRef]

57. Tsao, Y.-C.; Sheen, G.-J. Dynamic Pricing, Promotion and Replenishment Policies for a Deteriorating Item under Permissi-ble Delay in Payments. Comput. Oper. Res. 2008, 35, 3562-3580. [CrossRef]

58. Li, X.; Li, Y.; Govindan, K. An incentive model for closed-loop supply chain under the EPR law. J. Oper. Res. Soc. 2014, 65, 88-96. [CrossRef]

59. Song, H.; Chu, H. Incentive Strategies of Different Channels in an Electric Vehicle Battery Closed-Loop Supply Chain. Procedia Comput. Sci. 2019, 162, 634-641. [CrossRef]

60. Manouchehrabadi, M.K.; Yaghoubi, S. A game theoretic incentive model for closed-loop solar cell supply chain by considering government role. Energy Sour. Part A Recover. Util. Environ. Eff. 2020, 1-25. [CrossRef]

61. Wang, X.; Zhang, Z.; Yang, L.; Zhao, J. Price and capacity decisions in a telemedicine service system under government subsidy policy. Int. J. Prod. Res. 2021, 59, 5130-5143. [CrossRef]

62. Che, C.; Zhang, X.; Chen, Y.; Zhao, L.; Zhang, Z. A Model of Waste Price in a Symbiotic Supply Chain Based on Stackelberg Algorithm. Sustainability 2021, 13, 1740. [CrossRef]

63. Wan, G.; Kou, G.; Li, T.; Xiao, F.; Chen, Y. Pricing Policies in a Retailer Stackelberg O2O Green Supply Chain. Sustainability 2020, 12, 3236. [CrossRef]

64. Su, J.; Li, C.; Tsai, S.-B.; Lu, H.; Liu, A.; Chen, Q. A Sustainable Closed-Loop Supply Chain Decision Mechanism in the Elec-tronic Sector. Sustainability 2018, 10, 1295. [CrossRef]

65. Li, Z.; Xu, Y.; Deng, F.; Liang, X. Impacts of Power Structure on Sustainable Supply Chain Management. Sustainability 2017, 10, 55. [CrossRef]

66. Shevchenko, T.; Laitala, K.; Danko, Y. Understanding Consumer E-Waste Recycling Behavior: Introducing a New Economic Incentive to Increase the Collection Rates. Sustainability 2019, 11, 2656. [CrossRef]

67. Wang, Y.; Wiegerinck, V.; Krikke, H.; Zhang, H. Understanding the Purchase Intention towards Remanufactured Product in Closed-Loop Supply Chains: An Empirical Study in China. Int. J. Phys. Distrib. Logist. Manag. 2013, 43, 866-888. [CrossRef]

68. Chen, J.-M.; Chang, C.-I. Dynamic pricing for new and remanufactured products in a closed-loop supply chain. Int. J. Prod. Econ. 2013, 146, 153-160. [CrossRef]

69. Gan, S.-S.; Pujawan, I.N.; Widodo, B. Pricing decision for new and remanufactured product in a closed-loop supply chain with separate sales-channel. Int. J. Prod. Econ. 2017, 190, 120-132. [CrossRef]

70. Awan, U. Industrial Ecology in Support of Sustainable Development Goals. In Encyclopedia of the UN Sustainable Development Goals; Springer: Cham, Switzerland, 2020; pp. 370-380. 
71. Zhen, L.; Huang, L.; Wang, W. Green and sustainable closed-loop supply chain network design under uncertainty. J. Clean. Prod. 2019, 227, 1195-1209. [CrossRef]

72. Sun, X.; Zhou, Y.; Li, Y.; Govindan, K.; Han, X. Differentiation competition between new and remanufactured products considering third-party remanufacturing. J. Oper. Res. Soc. 2020, 71, 161-180. [CrossRef] 